\title{
Histomorphological analysis of the variability of the human skeleton: forensic implications
}

Marco Cummaudo ${ }^{1,2}$ MSc, Annalisa Cappella ${ }^{1} \mathrm{PhD}$, Miranda Biraghi ${ }^{1} \mathrm{BSc}$, Caterina Raffone ${ }^{1} \mathrm{MSc}$, Nicholas Márquez-Grant ${ }^{2} \mathrm{PhD}$, Cristina Cattaneo ${ }^{1} \mathrm{MSc}, \mathrm{MD}, \mathrm{PhD}$

${ }^{1}$ LABANOF (Laboratorio di Antropologia e Odontologia Forense) Dipartimento di Scienze Biomediche per la Salute, Via Mangiagalli n.37, 20133 University of Milan, Italy

${ }^{2}$ Cranfield Forensic Institute, Cranfield University, Defence Academy of the United Kingdom, Shrivenham, UK

Abbreviated title: Histomorphology of the human skeleton

Keywords: Forensic Anthropology; Bone histology; Human vs non-human

Corresponding author: Marco Cummaudo - LABANOF (Laboratorio di Antropologia e Odontologia Forense) Dipartimento di Scienze Biomediche per la Salute, Via Mangiagalli n.37, 20133 University of Milan, Italy.

Phone number: +393408009986; email address: m.cummaudo@cranfield.ac.uk

\section{Abstract \\ Objectives}

One of the fundamental questions in forensic medicine and anthropology is whether or not a bone or bone fragment is human. Surprisingly at times for the extreme degradation of the bone (charred, old) DNA cannot be successfully performed and one must turn to other methods. Histological analysis at times can be proposed. However, the variability of the single human skeleton has never been tested.

Recent studies on the diagnosis of species by histomorphological analysis of bone fragments have focused generally on a few skeletal elements, such as the femur, tibia and ribs. This study aims to verify whether or not there are significant differences in the histomorphology throughout a human adult skeleton and in different portions of the same bone.

\section{Materials and methods}

Forty-nine thin sections of long, flat and irregular bones were obtained from a well preserved medieval adult human skeleton. A qualitative histomorphological analysis was performed in order to assess the presence of primary and secondary bone and the presence, absence and orientation of vascular canals.

Results 
No histological sections exhibited woven or fibro-lamellar bone. Long bones showed a higher variability with an alternation within the same section of areas characterized by tightly packed secondary osteons and areas with scattered secondary osteons immersed in a lamellar matrix.

Flat and irregular bones appeared to be characterized by a greater uniformity with scattered osteons in abundant interstitial lamellae. Some cases of "osteon banding" and "drifting osteons" were observed.

\section{Discussion}

Although Haversian bone represent the most frequent pattern, a histomorphological variability between different bones of the same individual, in different portions of the same bone and in different parts of the same section has been observed.

Therefore, the present study has highlighted the importance of extending research to whole skeletons without focusing only on single bones, in order to have a better understanding of the histological variability of both human and non-human bone.

\section{Introduction}

One of the fundamental questions in forensic anthropology is whether or not a bone or bone fragment is human. In recent years, several studies have focused on species identification of bone fragments by histological analysis providing morphological descriptions of the bone tissue in different species (Brits et al., 2014; Cuijpers 2006; Cuijpers, 2009; Hilllier and Bell, 2007; Locke 2004; Mulhern and Ubelaker, 2001; Sawada et al., 2014). Regression formulas to distinguish between human and non-human Haversian systems have also been published (Cattaneo et al., 2009; Crescimanno and Stout, 2012; Dominguez and Crowder 2012; Martiniaková et al., 2006a,b; Martiniaková et al., 2007a,b).

Nonetheless, although bone histology has been explored since at least the $17^{\text {th }}$ century with the research by Clopton Havers (1691), a number of general biology and histology textbooks still mention Haversian bone only when considering bone tissue types (Locke and Dean, 2003). The latter leaves out the great variability that exists between (a) different species; (b) different bones of the same skeleton; (c) different parts of the same bone; (d) different areas of the same section; (e) and at different differences according to age (Enlow, 1966).

Recently, Cuijpers (2006) has developed a classification system of bone tissue types that derives from previous work by Francillon-Vieillot et al. (1990) on the microstructure of vertebrate skeletal tissues. This classification takes into account three different criteria: the organization of the bone matrix (non-lamellar, lamellar), the type of vascularization (e.g. avascular, radial vascular canals) and the type of bone deposition (primary or secondary). Primary bone consists of new bone laid down in layers during the appositional growth and is divided according to the composition of the bone matrix between non-lamellar tissue or fibrous bone; and circumferential lamellar bone.

On the one hand, non-lamellar tissue or fibrous bone refers to tissue whose matrix may be either "woven" or "parallel fibered" in composition. Woven bone generally contains randomly distributed osteocytes (Enlow, 
1966; Francillon-Vieillot et al., 1990). Under polarized light woven bone shows general isotropy and does not exhibit birefringence. This bone tissue is associated with rapid osteogenesis and it's produced in periods of immediate need, such as embryonic growth, during repair processes and in response to pathological conditions (Enlow, 1966; Hillier and Bell, 2007).

On the contrary "parallel fibered" bone matrix is characterized by fibers which are oriented in the same plane and bone lacunae with a regular arrangement (Enlow, 1966; Francillon-Vieillot et al., 1990).

Circumferential lamellar bone, on the other hand, is a tissue whose matrix is deposited in the form of lamellae and gradually replaces the natal woven bone. Each lamella is composed of collagen fibers which have a different orientation compared to that of the fibers of the previous lamella (Locke and Dean, 2003).

This bone can be divided into outer and inner circumferential lamellae which are respectively located directly underneath the periosteum and on the inner surface of the bone adjacent to the endosteum (Urbanová and Novotný, 2003; Zoetis et al., 2003). This type of tissue has a high spatial organization due to the slower time of deposition compared with non-lamellar bone tissue (Hillier and Bell, 2007). Under polarized light lamellae show anisotropy with an alternation of light and dark due to the different orientation of collagen fibers (Francillon-Vieillot et al., 1990).

Both the lamellar bone and the fibrous bone may be devoid of vascularization (avascular tissue) or present various degrees of vascularization. The vascular canals, lamellar bone and fibrous bone are divided into further subcategories based on the orientation of the canals, namely (Cuijpers, 2006; Francillon-Vieillot et al., 1990): longitudinal, circular, reticular and radial.

The secondary bone, as opposed to primary bone which is deposited in a zone where bone tissue has not existed, is laid in areas where existing bone is resorbed. Its division into subcategories is done according to the density of secondary osteons and their organization. Secondary osteons, also called Haversian systems, have their origin in a central cavity called Haversian canal which contains blood vessels and nerves surrounded by a lamellar bone matrix (Enlow, 1962). When compared with primary osteons, the secondary osteons are recognizable since they are bordered by a cement line; this is the outermost lamella and is the last to be deposited (Crescimanno and Stout, 2012; Francillon-Vieillot et al., 1990). In secondary bone tissue, the Haversian systems can be separated by interstitial lamellae or tightly packed with little or no interstitial lamellae. When the osteons are scattered, they can be organized in a linear row surrounded by lamellar tissue (osteon banding), which is considered in the literature as a diagnostic feature to distinguish between human and non-human bone (Mulhern and Ubelaker, 2001).

When the osteons are tightly packed, these can be with no organization or arranged in rows roughly parallel to the medullary cavity.

Since the secondary bone is subject to bone remodelling, Haversian systems can have different morphological characteristics. Among these there are the "drifting osteons", which are secondary osteons in which continuous resorption takes place from one side and deposition to the other (Streeter, 2011; Robling and Stout, 1999). The resultant effect is an osteon with a sort of tail formed by the lamellae. Other types of 
secondary osteons include "embedded" osteons and "double-zonal" osteons (Crescimanno and Stout, 2012; Robling and Stout, 1999).

Considering all the different types of bone tissues and the existing literature, it is not possible to assume that the human skeleton exhibits exclusively Haversian bone, as well as skeletons of other vertebrates are not characterized by plexiform bone only.

In fact, recent studies on on the diagnosis of species by histomorphological analysis have mainly focused on some specific skeletal elements, such as the femur, tibia and rib (Brits et al., 2014; Cuijpers, 2006; Cuijpers, 2009; Locke, 2004; Martiniaková et al., 2006b). At present, no study has ever examined systematically bone histomorphology of an entire human skeleton.

Cortical bone is characterized by a nonuniform strain distribution which is a consequence of a bone's function (Skedros, 2011). This may affect bone microscopic structure of the different bones of the skeleton. Therefore, the present study aims to map histologically the human skeleton in order to shed light on the histomorphological variability throughout the skeleton and in different locations of the same bone by assessing and comparing the different tissue typologies.

Having a better understanding of the variability of human bone tissue is paramount in order to perform species discrimination on bone fragments in medico-legal cases to determine if a bone is human or not.

\section{Materials and methods}

Bone samples were taken from a medieval adult human skeleton (Fig. 1) which was recovered in 1981 during an archaeological excavation by Lombardia Archaeological Superintendency at San Martino di Serravalle's church, in the north of Italy (Brogiolo and Mariotti, 2009). A morphological analysis to estimate the age at death and sex estimation following a number of techniques (Beauthier et al., 2010; Brooks and Suchey, 1990; Buikstra and Ubelaker, 1994; İscan et al., 1984; Rougé-Maillart et al., 2009), revealed that the skeletal remains belonged to a Caucasoid male individual aged between 25 and 46 years without any obvious pathological conditions, except an osteoma which was identified on the right zygomatic arch. The skeleton was well preserved with only slight weathering on the epiphysis of long bones. [Figure 1 here]

The method used in this study to produce bone thin sections was based on a standard bone preparation (Maat et al., 2001). Forty-nine samples $5 \mathrm{~mm}$ thick were taken along the entire skeleton including long bones, flat bones, short bones and irregular bones (Table 1). [Table 1 here] Each section was obtained by making two parallel cuts, perpendicular to the long axis of the bone using a hack saw. The section was then embedded in Pertex resin (Histo-Line, Milan, Italy) on a glass slide, grounded and polished on a Struers DAP-7 grinding wheel for geologists, using different abrasive papers graded 180, 320, 600, 1200, 2400 and 4000.

Cross sections were observed with an Axio Scope.A1 light microscope, at 25X, 100X and 200X magnification and photos were taken using IScapture ${ }^{\circledR}$ software.

The main concern related to the use of an archaeological skeleton regards the possibility that bone histological changes had occurred through time due to microbiological attack (Booth and Madgwick, 2016; 
Dixon et al., 2008; Jans et al., 2004; Müller et al., 2011). As a consequence, "microscopic focal destruction" (MFD) can easily hinder the analysis of bone microscopic structure.

Although the skeleton dates back to the High Medieval Period, no signs of MFD (Jans et al., 2004; Müller et al., 2011) were found in its histological structure making it suitable for further study.

Given the good preservation of the histological bone structure [Oxford Histological Index 5 (Hedges et al., 1995)] several samples were taken along the entire skeleton including long bones, flat bones and irregular bones (Table 1). Moreover, since most of the previous studies (Brits et al., 2014; Crescimanno and Stout, 2012; Locke, 2004; Martiniaková et al., 2006b; Urbanová and Novotný, 2005) have focused exclusively on the midshaft of long bones, samples from other parts of the same bone were taken (e.g. proximal and distal diaphysis).

A qualitative histomorphological analysis of the entire cross sections was performed in order to assess the variability of the histological structure in different part of the skeleton. Bone tissue microstructure was described following the classification systems and definitions of Enlow and Brown (1956) and FrancillonVieillot et al. (1990). The first distinction concerned the presence of primary (fibrous, fibro-lamellar or circumferential lamellar bone) and/or secondary bone (Haversian bone). Secondly the presence or absence and the orientation of the vascular canals was analyzed (avascular, longitudinal, circumferential, reticular or radial vascular canals). As regards secondary bone a distinction based on the secondary osteons arrangements was made (Francillon-Vieillot et al., 1990), distinguishing between dense or scattered, characterized respectively by tightly packed and few isolated and scattered osteons. In addition, the presence of "osteon banding" (Mulhern and Ubelaker, 2001) and "drifting osteons" (Robling and Stout, 1999) was reported.

\section{Results}

No histological sections exhibited woven or fibro-lamellar bone. As regards the Haversian tissue, the most frequent pattern ( $73 \%$ of the samples) is characterized by scattered secondary osteons with no organization (Table 2). [Table 2 here]

Approximately 50\% of the forty-nine sections showed primary circumferential lamellar bone in the form of outer and/or inner circumferential lamellae, respectively located at the periosteal and endosteal layers.

Generally, excluding the trabecular bone which consists of avascular or poorly vascularized lamellar tissue, the long bones showed a higher variability. Indeed, $50 \%$ of long bones exhibited an alternation within the same section of areas characterized by tightly packed secondary osteons and areas in which the Haversian systems are scattered and immersed in a lamellar matrix (Fig. 2). [Figure 2 here]

Some peculiarities have been observed, such as lamellar tissue with radial vascular canals in the distal metaphysis of the fibula (Fig. 3) and avascular lamellar tissue in the lateral portion of the diaphysis of the radius (Fig. 4). [Figures 3-4 here]

The observation of the histological sections by polarized light allowed the identification of several "drifting osteons" in the clavicle and the diaphysis of the ulna (Fig. 5). In the distal metaphysis of the humerus and the 
diaphysis of the femur, some cases of "osteon banding" were observed with rows of four or five secondary osteons (Fig. 6). [Figures 5-6 here]

On the contrary, flat and irregular bones appeared to be characterized by a greater uniformity since the majority of the cross sections (84\%) were characterized by a single pattern of osteon organization. Generally flat bones exhibited scattered secondary osteons with abundant interstitial lamellae, with the exception of the occipital, the rib, the sternum, the superior border of the scapula and the iliopubic ramus which were characterized by a greater osteon density with tightly packed secondary osteons and scarce interstitial lamellae. Petrous showed some peculiarities, such as a large network of reticular and longitudinal vascular canals along with a higher cellularity (lacunar density), which were not observed in any other section.

Concerning irregular bones such as mandible and vertebra, the most frequent pattern is lamellar tissue along with areas with few scattered secondary osteons and longitudinal vascular canals with the exception of the spinous process of the cervical vertebra which is characterized by a higher osteon density. Some cases of osteon banding (rows of $3 / 4$ osteons) have been observed in the mandible.

As regards the comparison between different portions of the same bone, the main differences are with regard to the density and organizations of the secondary osteons but these differences do not seem to follow a specific pattern.

\section{Discussion}

When skeletal remains are found, one of the questions forensic anthropologists have to address is whether a bone or bone fragment is of human origin. In fragmented remains, where macroscopic observation of the morphology and anatomical landmarks may be limited and biomolecular analysis is not possible, then histological analysis represents one approach to address the issue of species discrimination. Although the first studies on the histomorphology of human bones date back several hundred years and histological studies have increased in recent years in the forensic anthropology literature (Brits et al., 2009; Cattaneo et al., 2009; Crescimanno and Stout, 2012; Crowder and Stout, 2011; Cuijpers 2006; Cuijpers, 2009; Dominguez and Crowder, 2012; Martiniaková et al., 2006a,b; Martiniaková et al., 2007a,b), there are still many questions unanswered. Furthermore, from the existing literature, it seems evident that most of the studies regarding bone histology take into account mainly the diaphysis of a few long bones.

The histomorphological analysis on 49 cross-sections from a human adult skeleton showed the prevalence of secondary bone characterized by secondary osteons immersed in a lamellar matrix. No histological sections from throughout the skeleton showed fibrous bone which is typically found in embryonic bone, in fracture callus, and in response to pathological conditions such as bone neo-plasms (Currey, 2012; Hillier and Bell, 2007). 
Nonetheless a significant variability has been observed throughout the skeleton especially regarding the pattern of osteon organization with areas in which they are tightly packed and areas in which they are scattered in a lamellar matrix.

The difference in the Haversian system density between long bones confirms what has been reported in previous research regarding the relationship between the physical properties of bone and its histological structure (Evans and Bang, 1966). The femur and tibia showed a higher osteon density when compared to the fibula in which the Haversian systems are more scattered with higher number of interstitial lamellae probably due to a different load to which these bones are subject. Evans (1958) pointed out that a large number of small osteons and fragments make the tensile strength of a given amount of bone smaller if compared to areas with few large osteons and fragments. This is due to the abundance of cementing lines which are directly proportional to the number of osteons and represent areas of lower resistance to tensile failure. On the one hand, Haversian systems reduce the tensile strength and increase the tensile strain of cortical bone; on the other hand, interstitial lamellae reduce the tensile strain while increasing the tensile strength (Evans and Bang, 1966). This results in a greater tensile strength and elasticity of the fibula as compared with the femur and tibia.

Moreover, although flat bones seem generally characterized by scattered osteons, some exceptions have been reported. The rib, the sternum, the superior border of the scapula and the iliopubic ramus were characterised by large areas with tightly packed secondary osteons which may be related to muscular attachments such as internal intercostal and transverse thoracis (rib), pectoralis major (sternum), levator scapulae (scapula) and pectineus (iliopubic ramus). Similarly, the dense Haversian bone in correspondence of the spinous process of the cervical vertebra may be due the attachment of serratus posterior superior.

Furthermore, several sections showed areas with lamellar tissue with longitudinal vascular canals or avascular lamellar tissue whose presence apart from humans is attested also in non-human primates, cats, dogs and equids (Brits et al., 2014). This can present an issue when performing species identification on small bone fragments since the same tissue can be present in different species and there are no peculiar features which help to discriminate between them.

With regard to the differences in osteon organization in different portions of the same bone, no specific pattern was observed. Nonetheless these differences may be related to muscular or tendon attachment and/or the different loading to which different parts of bones are subjected to (Weiner et al. 1999).

The observation of the histological sections by polarized light allowed the identification of several drifting osteons in the diaphysis of the ulna, the diaphysis of the clavicle and the head of the rib.

Although it is still not clear, the stimulus to which the formation of drifting osteons can be attributed, they represent the most common type of osteon in subadult bones (Burton et al., 1989; Crowder and Stout, 2011; Robling and Stout, 1999).

The drifting osteons are Haversian systems which are characterized by continuous resorption on one side and continuous formation on the other. This makes the Haversian systems to become flattened in one plane and elongated transversely $t$ in the other plane with a "tail" of lamellae (Crowder and Stout, 2011; Robling and 
Stout, 1999). The finding of drifting osteons in the study sample is in accordance with the literature (Robling and Stout, 1999), since, although they are typical of juveniles, their presence in adult/older individuals is also attested.

Some of the samples, in particular those of the metaphysis of the humerus, the diaphysis of the femur and the mental protuberance of the mandible present "osteon banding". Osteon banding has been described as a typical non-human characteristic consisting of a distinct row of five or more primary or secondary osteons surrounded by lamellar tissue (Mulhern and Ubelaker, 2001), particularly frequent in sheep, equids and nonhuman primates (Brits et al., 2014). In accordance with the literature (Brits et al., 2014; Cuijpers 2009; Mulhern and Ubelaker, 2001), in the study sample rows of maximum four secondary osteons have been noted.

The present study has pointed out the existing histomorphological variability between different bones of the same individual, in different portion of the same bone and in different part of the same section.

Therefore, this study highlights the importance of studying the entire skeleton from a histological perspective in order to have a better understanding of the histological variability of both human and non-human bone.

Similar studies should take into account the variability between human individuals at different ages. Caccia et al. (2015) indeed, demonstrated that plexiform bone, generally considered a typical non-human bone tissue, can also be found in human infants ( $<1$ year of age).

A similar approach should apply to histomorphometric analysis since all the regression formulas commonly used for the diagnosis of species (Cattaneo et al., 2009; Martiniaková et al., 2006a; Martiniaková et al., 2007b; Crescimanno and Stout, 2012; Urbanová and Novotný, 2005) are based on measurements of osteon parameters mainly taken on long bones, without considering the possible histomorphometric variability between different bones. Secondary osteons from irregular or flat bones may be significantly different in dimensions when compared to what has been previously reported in literature (Cattaneo et al., 2009; Martiniaková et al., 2006a; Martiniaková et al., 2007b; Crescimanno and Stout, 2012; Urbanová and Novotný, 2005), undermining the reliability of the current methods of species discrimination.

As regards drifting osteons, nothing is known at the moment about their presence or absence in non-human bone. If they were only found in human bone, they could represent an important feature for the diagnosis of species.

Given the above scenario the authors suggest caution when performing species identification in forensic anthropology and medico-legal investigations by histological analysis until further studies shed light on the histomorphology and histomorphometry of the skeletal sites for which there is not yet a thorough understanding.

\section{References}

Brits D., Steyn M., L'Abbe, E.N. (2014). A histomorphological analysis of human and non-human femora. International Journal of Legal Medicine, 128(2), 369-377. 
Beauthier J.P., Lefèvre P., Meunier M., Orban R., Polet C., Werquin J.P., Quatrehomme G. (2010). Palatine Sutures as an Age Indicator: A Controlled Study in Elderly, Journal of Forensic Sciences, 55, 153-158.

Booth T.J., Madgwick R. (2016). New evidence for diverse secondary burial practices in Iron Age Britain: A histological case study. Journal of Archaeological Science, 67, 14-24.

Brogiolo G.P., Mariotti V. (2009). San Martino di Serravalle e San Bartolomeo De Castelàz. Due chiese di Valtellina: scavi e ricerche. Milano: Fondazione Gruppo Credito Valtellinese.

Brooks S., Suchey J. (1990). Skeletal age determination base on the os pubis: a comparison of the AcsádiNemeskéri and Suchey-Brooks methods. Journal of Human Evolution, 5, 227-238.

Buikstra, J.E., Ubelaker D.H. (1994). Standards for data collection from human skeletal remains: proceedings of a seminar at the field museum of natural history. Fayetteville: Arkansas Archaeological Survey Press.

Burton P., Nyssen-Behets C., Dhem A. (1989). Haversian bone remodeling in human fetus. Acta Anatomica (Basel), 135, 171-175.

Caccia G., Magli F., Tagi V.M., Porta D.G.A., Cummaudo M., Marquez-Grant N., Cattaneo C. (2015). Histological determination of the human origin from dry bone: a cautionary note for subadults. International Journal of Legal Medicine, 130(1), 299-307.

Cattaneo C., Porta D., Gibelli D., Gamba C. (2009). Histological determination of the human origin of bone fragments. Journal of Forensic Sciences, 54, 531-533.

Crescimanno A., Stout S.D. (2012). Differentiating fragmented human and nonhuman long bone using osteon circularity. Journal of Forensic Sciences, 57(2), 287-294.

Crowder C., Stout S. (2011). Bone histology: an anthropological perspective. CRC Press, Boca Raton.

Cuijpers A.G.F.M. (2006). Histological identification of bone fragments in archaeology: Telling humans apart from horses and cattle. International Journal of Osteoarchaeology, 16, 465-480.

Cuijpers A.G.F.M. (2009). Distinguishing between the bone fragments of medium-sized mammals and children. A histological identification method for archaeology. Anthropologischer Anzeiger, 67(2), 181-203

Currey J.D. (2012). The structure and mechanics of bone. Journal of Materials Science, 47(1), 41-54.

Dixon R., Dawson L., Taylor D. (2008, October). The experimental degradation of archaeological human bone by anaerobic bacteria and the implications for recovery of ancient DNA. In: The 9th International Conference on Ancient DNA and Associated Biomolecules, Pompeii, Italy.

Dominguez V.M., Crowder C.M. (2012). The utility of osteon shape and circularity for differentiating human and non-human Haversian bone. American Journal of Physical Anthropology, 149(1), 84-91.

Enlow D.H., Brown S.O. (1956). A comparative histological study of fossil and recent bone tissues, part I. Texas Journal of Science, 7, 405-443.

Enlow, D.H. (1962). A study of the post-natal growth and remodeling of bone. American Journal of Anatomy, 110(2), 79-101.

Enlow D. (1966). An evaluation of the use of bone histology in forensic medicine and anthropology. In Evans F.G. (ed.), IIIrd International Congress of Anatomists: Symposium on Joints and Bones. Springer Verlag, 92-112.

Evans F.G. (1958). Relations between the microscopic structure and tensile strength of human bone. Acta Anatomica (Basel), 35, 285-301. 
Evans F.G., Bang S. (1966). Physical and histological differences between human fibular and femoral compact bone. In Evans F.G. (ed.), Studies on the anatomy and function of bones and joints (pp. 142-155). Berlin: Springer-Verlag.

Francillon-Vieillot H., de Buffrénil V., Castanet J., Géraudie J., Meunier F.J., Sire J., Zylberberg L., de Ricqlès A. (1990). Microstructure and mineralization of vertebrate skeletal tissues. In: Carter J.G. (ed.), Skeletal biomineralization: patterns, processes and evolutionary trends (pp. 471-530). New York: Van Nostrand Reinhold.

Havers C. (1691). Osteologia nova, or some new observations of the bones. London: printed for Samuel Smith.

Hedges R.E.M., Millard A.R., Pike A.W.G. (1995). Measurements and relationships of diagenetic alteration of bone from three archaeological sites. Journal of Archaeological Science, 22, 201-209.

Hillier M.L., Bell L.S. (2007). Differentiating human bone from animal bone: a review of histological methods. Journal of Forensic Sciences, 52(2), 249-263.

Iscan M.Y., Loth S.R., Wright R.K. (1984). Age estimation from the rib by phase analysis: white males. Journal of Forensic Sciences, 29(4), 1094-1104.

Jans M.M.E., Nielsen-Marsh C.M., Smith C.I., Collins M.J., Kars H. (2004). Characterisation of microbial attack on archaeological bone. Journal of Archaeological Science, 31(1), 87-95.

Locke M., Dean R.L. (2003). Vascular spaces in compact bone: a technique to correct a common misinterpretation of structure. The American Biology Teacher, 65, 701-707.

Locke M. (2004). Structure of long bones in mammals. Journal of Morphology, 262, 546-565.

Maat G.J.R., Van Den Bos R.P.M., Aarents M.J. (2001). Manual preparation of ground sections for the microscopy of natural bone tissue: Update and modification of Frost's "rapid manual method." International Journal of Osteoarchaeology, 11(5), 366-374.

Martiniaková M., Grosskopf B., Omelka R., Vondráková M., Bauerová M., (2006a). Differences among species in compact bone tissue microstructure of mammalian skeleton: use of a discriminant function analysis for species identification. Journal of Forensic Sciences, 51(6), 1235-1239.

Martiniaková M., Grosskopf B., Vondráková M., Omelka R., Fab̌̌s M. (2006b). Differences in femoral compact bone tissue microscopic structure between adult cows (Bos taurus) and pigs (Sus scrofa domestics). Anatomia, Histologia, Embryologia, 35, 167-170.

Martiniaková M., Grosskopf B., Omelka R., Vondráková M., Bauerová M. (2007a). Histological analysis of ovine compact bone tissue. The Journal of Veterinary Medical Science, 69, 409-411.

Martiniaková M., Grosskopf B., Omelka R., Dammers K., Vondráková M., Bauerová M. (2007b). Histological study of compact bone tissue in some mammals: a method for species determination. International Journal of Osteoarchaeology, 17,82-90.

Mulhern D.M., Ubelaker D.H. (2001). Differences in osteon banding between human and nonhuman bone. Journal of Forensic Sciences, 46(2), 220-222.

Müller K., Chadefaux C., Thomas N., Reiche I. (2011). Microbial attack of archaeological bones versus high concentrations of heavy metals in the burial environment. A case study of animal bones from a mediaeval copper workshop in Paris. Palaeogeography, Palaeoclimatology, Palaeoecology, 310(1-2), 39-51. 
Robling A.G., Stout S.D. (1999). Morphology of the drifting osteon. Cells Tissues Organs, 164(4), 192-204.

Rougé-Maillart C., Vielle B., Jousset N., Chappard D., Telmon N., Cunha E. (2009). Development of a method to estimate skeletal age at death in adults using the acetabulum and the auricular surface on a Portuguese population. Forensic Science International, 188(1-3), 91-95.

Sawada J., Nara T., Fukui J., Dodo Y., Hirata K. (2014). Histomorphological species identification of tiny bone fragments from a paleolithic site in the northern Japanese archipelago. Journal of Archaeological Sciences, 46, 270-280.

Skedros J.G. (2011). Interpreting load history in limb-bone diaphyses: important considerations and their biomechanical foundations. In: Crowder C., Stout S. (eds.), Bone histology: an anthropological perspective (pp. 153-220). CRC Press, Boca Raton.

Streeter M. (2011). Histological age-at-death estimation. In: Crowder C., Stout S. (eds.), Bone histology: an anthropological perspective (pp. 135-152). CRC Press, Boca Raton.

Urbanová P., Novotný V. (2005). Distinguishing between human and non-human bones: histometric method for forensic anthropology. Anthropologie, 43, 77-85.

Weiner S., Traub W., Wagner H.D. (1999). Lamellar bone: structure-function relations. Journal of Structural Biology, 126, 241-255.

Zoetis T., Tassinari M.S., Bagi C., Walthall K., Hurtt M.E. (2003). Species Comparison of Postnatal Bone Growth and Development. Birth Defects Research. Part B, Developmental and Reproductive Toxicology, 68(2), 86-110.

\section{List of figures:}

Figure 1 - Study sample - an archaeological human adult skeleton with no apparent pathology/pathological conditions.

Figure 2 - Ulna (diaphysis) - (a) dense secondary osteons in the lateral portion; (b) scattered secondary osteons with no organization in the medial portion, $25 \mathrm{X}$ magnification.

Figure 3 - Fibula (distal metaphysis) - lamellar tissue with radial vascular canals (white arrows), 25X magnification.

Figure 4 - Radius (diaphysis) - avascular lamellar tissue (white arrow), 25X magnification.

Figure 5 - Ulna (diaphysis) - several drifting osteons, 100X magnification. Polarized light.

Fig. 6 - Humerus, distal metaphysis - row of four secondary osteons. 100x magnification. Polarized light.

Table 1 - Study sample (PM=proximal metaphysis; $\mathrm{D}=$ diaphysis; $\mathrm{DM}=$ distal metaphysis). 


\begin{tabular}{|c|c|}
\hline \multirow{9}{*}{$\begin{array}{l}0 \\
\tilde{\Xi} \\
0 \\
0 \\
\Xi \\
0\end{array}$} & Humerus (PM, D, DM) \\
\hline & Ulna (PM, D, DM) \\
\hline & Radius (PM, D, DM) \\
\hline & Clavicle (medial end, D, lateral end) \\
\hline & Femur (neck, PM, D, DM) \\
\hline & Tibia (PM, D, DM) \\
\hline & Fibula (PM, D, DM) \\
\hline & Metacarpal (base, shaft, head) \\
\hline & Metatarsal (base, shaft, head) \\
\hline \multirow{12}{*}{ 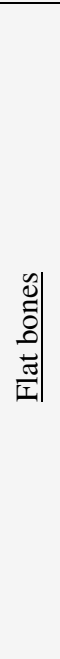 } & Glabella \\
\hline & Zygomatic process of frontal bone \\
\hline & Parietal (middle portion) \\
\hline & Occipital \\
\hline & Petrous (temporal bone) \\
\hline & Scapula superior border \\
\hline & Scapula acromion \\
\hline & Sternum \\
\hline & Rib (head, body) \\
\hline & Iliac crest (longitudinal, transversal) \\
\hline & Ischiopubic ramus \\
\hline & Iliopubic ramus \\
\hline : & Patella (sagittally) \\
\hline \multirow{4}{*}{ 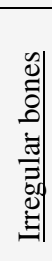 } & Gonion (mandible) \\
\hline & Mental protuberance (mandible) \\
\hline & Mandibular condyle (mandible) \\
\hline & $\begin{array}{l}\text { Cervical vertebra (longitudinal, transversal, spinous } \\
\text { process) }\end{array}$ \\
\hline
\end{tabular}

Table 1 - Study sample (PM=proximal metaphysis;

$\mathrm{D}=$ diaphysis; $\mathrm{DM}=$ distal metaphysis) 
Table 2 - Results of the histomorphological analysis.

\begin{tabular}{|c|c|c|c|c|c|c|c|c|c|c|c|c|c|c|c|c|c|c|}
\hline \multirow{3}{*}{ 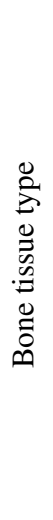 } & \multirow{3}{*}{ Bone } & \multicolumn{4}{|c|}{ Primary bone } & \multicolumn{8}{|c|}{ Secondary bone } & \multicolumn{5}{|c|}{ Vascularization } \\
\hline & & \multicolumn{2}{|c|}{ 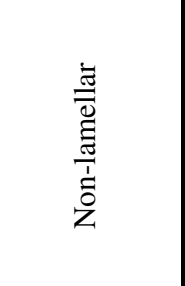 } & \multicolumn{2}{|c|}{ 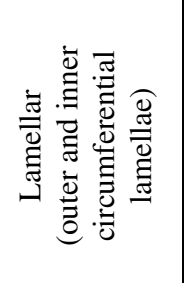 } & \multicolumn{2}{|c|}{ 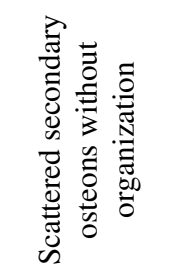 } & \multicolumn{2}{|c|}{ 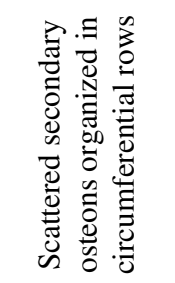 } & \multicolumn{2}{|c|}{ 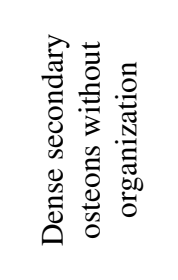 } & \multicolumn{2}{|c|}{ 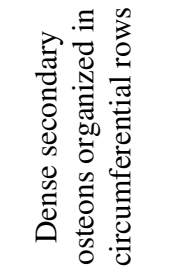 } & \multirow{2}{*}{ 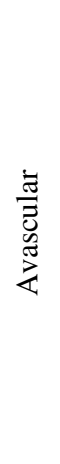 } & \multirow{2}{*}{ 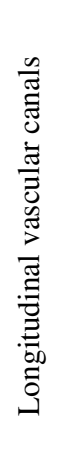 } & \multirow{2}{*}{ 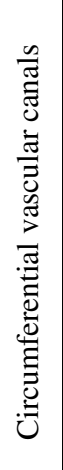 } & \multirow{2}{*}{ 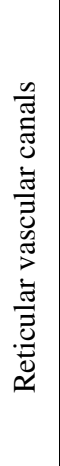 } & \multirow{2}{*}{ 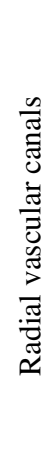 } \\
\hline & & 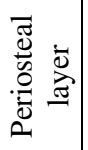 & 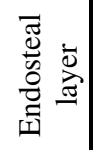 & 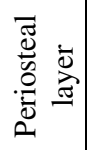 & 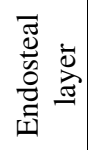 & 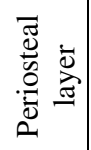 & 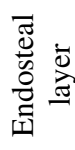 & 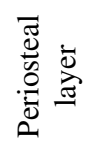 & 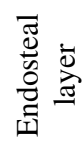 & 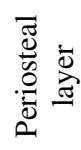 & 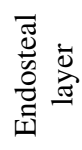 & 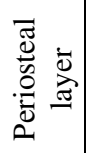 & 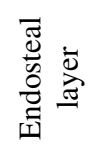 & & & & & \\
\hline \multirow{28}{*}{$\begin{array}{l}0 \\
0 \\
0 \\
00 \\
0 \\
0\end{array}$} & Humerus - proximal metaphysis & & & & $\checkmark$ & $\checkmark$ & $\checkmark$ & $\checkmark$ & & & & & & & $\checkmark$ & & & \\
\hline & Humerus - diaphysis & & & $\checkmark$ & & $\checkmark$ & $\checkmark$ & & & $\checkmark$ & $\checkmark$ & & & & $\checkmark$ & & & \\
\hline & Humerus - distal metaphysis & & & & & $\checkmark$ & $\checkmark$ & & & $\checkmark$ & $\checkmark$ & & & & & & & \\
\hline & Ulna - proximal metaphysis & & & & & & & $\checkmark$ & & $\checkmark$ & $\checkmark$ & & & & & & & \\
\hline & Ulna - diaphysis & & & $\checkmark$ & & $\checkmark$ & $\checkmark$ & $\checkmark$ & & $\checkmark$ & $\checkmark$ & & & & & & & \\
\hline & Ulna - distal metaphysis & & & & & $\checkmark$ & $\checkmark$ & & & & & & & & & & & $\checkmark$ \\
\hline & Radius - proximal metaphysis & & & & & & & & & $\checkmark$ & $\checkmark$ & $\checkmark$ & & & & & & \\
\hline & Radius - diaphysis & & & $\checkmark$ & $\checkmark$ & $\checkmark$ & & & & & & $\checkmark$ & & $\checkmark$ & $\checkmark$ & & & \\
\hline & Radius - distal metaphysis & & & $\checkmark$ & & $\checkmark$ & $\checkmark$ & & & & & & & & & & & \\
\hline & Clavicle - medial end & & & $\checkmark$ & $\checkmark$ & $\checkmark$ & $\checkmark$ & & & $\checkmark$ & & & & & $\checkmark$ & & & \\
\hline & Clavicle - diaphysis & & & $\checkmark$ & & & & & & & & $\checkmark$ & & & & & & \\
\hline & Clavicle - lateral end & & & & & & $\checkmark$ & & & $\checkmark$ & $\checkmark$ & & & & & & & \\
\hline & Femur - neck & & & & & & & & & & $\checkmark$ & $\checkmark$ & $\checkmark$ & & & & & \\
\hline & Femur - proximal metaphysis & & & & & & & & & $\checkmark$ & $\checkmark$ & & & & & & & \\
\hline & Femur - diaphysis & & & & & & & & $\checkmark$ & $\checkmark$ & $\checkmark$ & $\checkmark$ & & & & & & \\
\hline & Femur - distal metaphysis & & & & $\checkmark$ & $\checkmark$ & $\checkmark$ & & & & & & & & $\checkmark$ & & & \\
\hline & Tibia proximal metaphysis & & & & & $\checkmark$ & $\checkmark$ & & & $\checkmark$ & $\checkmark$ & & & & & & & \\
\hline & Tibia - diaphysis & & & $\checkmark$ & $\checkmark$ & & & & & $\checkmark$ & $\checkmark$ & $\checkmark$ & & & $\checkmark$ & & & \\
\hline & Tibia - distal metaphysis & & & $\checkmark$ & $\checkmark$ & $\checkmark$ & $\checkmark$ & & & $\checkmark$ & $\checkmark$ & $\checkmark$ & & & $\checkmark$ & & & \\
\hline & Fibula - proximal metaphysis & & & & & $\checkmark$ & $\checkmark$ & & & $\checkmark$ & & & & & & & & \\
\hline & Fibula - diaphysis & & & & & & $\checkmark$ & & & $\checkmark$ & $\checkmark$ & $\checkmark$ & & & & & & \\
\hline & Fibula-distal metaphysis & & & $\checkmark$ & & $\checkmark$ & $\checkmark$ & & & & & & & & & & & $\checkmark$ \\
\hline & Metacarpal - proximal end & & & $\checkmark$ & $\checkmark$ & & & & & & & & & & & & & \\
\hline & Metacarpal - shaft & & & $\checkmark$ & $\checkmark$ & & $\checkmark$ & & & & & $\checkmark$ & $\checkmark$ & & & & & \\
\hline & Metacarpal - distal end & & & $\checkmark$ & $\checkmark$ & & & & & & & $\checkmark$ & $\checkmark$ & & & & & \\
\hline & Metatarsal - proximal end & & & & & $\checkmark$ & $\checkmark$ & & & & & & & & & & & \\
\hline & Metatarsal - shaft & & & & & & $\checkmark$ & & & $\checkmark$ & $\checkmark$ & & & & & & & \\
\hline & Metatarsal - distal end & & & $\checkmark$ & $\checkmark$ & $\checkmark$ & $\checkmark$ & & & & & & & & & & & \\
\hline
\end{tabular}




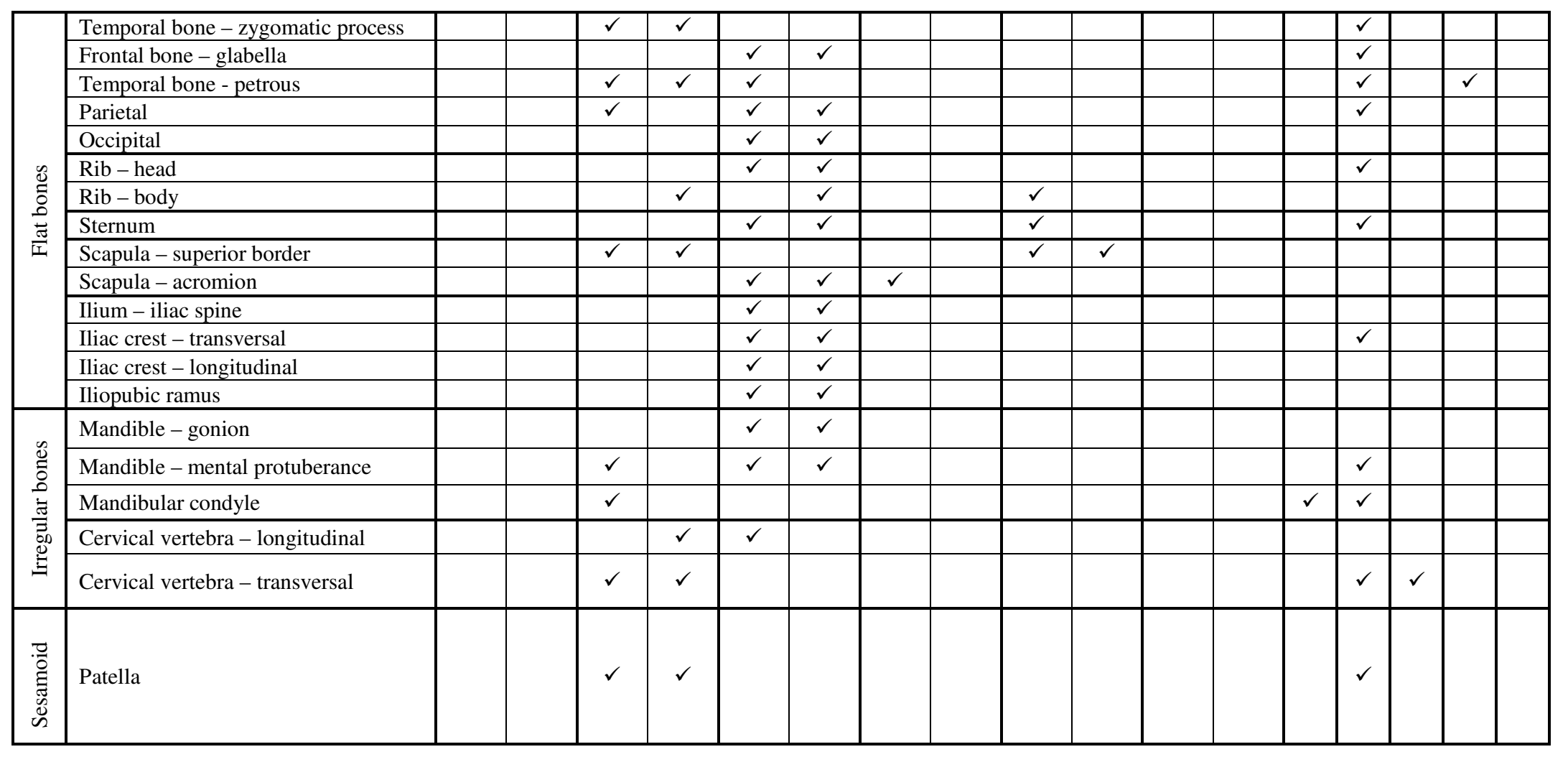

Table 2 - Results of the histomorphological analysis. 


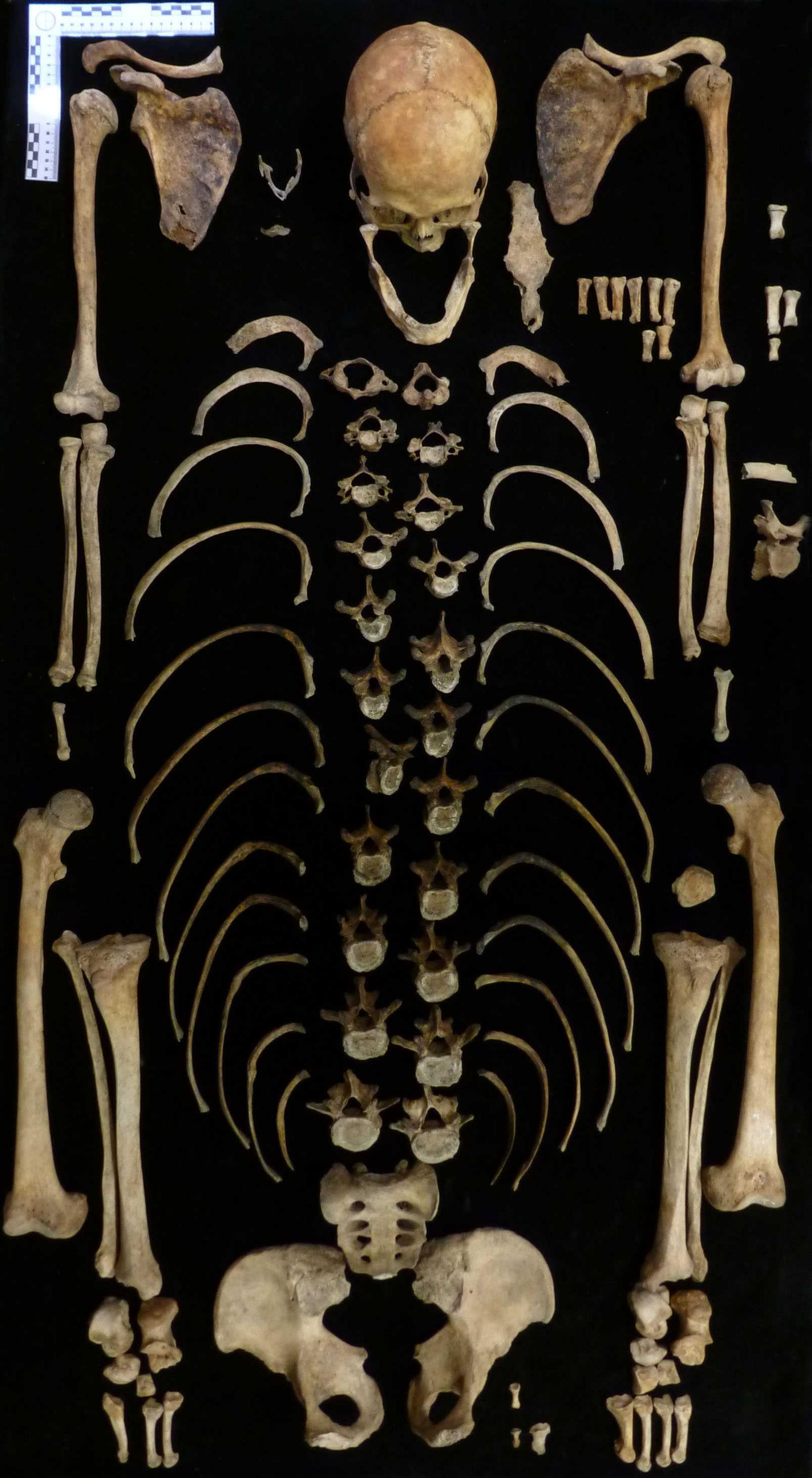




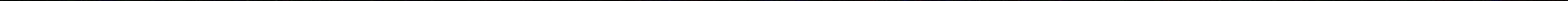




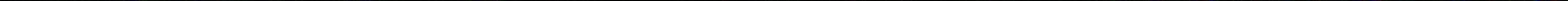

